IZA DP No. 6014

Evidence on the Long Shadow of Poor Mental Health across Three Generations

David W. Johnston

Stefanie Schurer

Michael A. Shields

October 2011 


\title{
Evidence on the Long Shadow of Poor Mental Health across Three Generations
}

\author{
David W. Johnston \\ CHE, Monash University \\ Stefanie Schurer \\ Victoria University of Wellington \\ Michael A. Shields \\ CHE, Monash University, \\ University of Melbourne and IZA
}

\section{Discussion Paper No. 6014 \\ October 2011}

\author{
IZA \\ P.O. Box 7240 \\ 53072 Bonn \\ Germany \\ Phone: +49-228-3894-0 \\ Fax: +49-228-3894-180 \\ E-mail: iza@iza.org
}

Any opinions expressed here are those of the author(s) and not those of IZA. Research published in this series may include views on policy, but the institute itself takes no institutional policy positions.

The Institute for the Study of Labor (IZA) in Bonn is a local and virtual international research center and a place of communication between science, politics and business. IZA is an independent nonprofit organization supported by Deutsche Post Foundation. The center is associated with the University of Bonn and offers a stimulating research environment through its international network, workshops and conferences, data service, project support, research visits and doctoral program. IZA engages in (i) original and internationally competitive research in all fields of labor economics, (ii) development of policy concepts, and (iii) dissemination of research results and concepts to the interested public.

IZA Discussion Papers often represent preliminary work and are circulated to encourage discussion. Citation of such a paper should account for its provisional character. A revised version may be available directly from the author. 
IZA Discussion Paper No. 6014

October 2011

\section{ABSTRACT \\ Evidence on the Long Shadow of Poor Mental Health across Three Generations}

Individuals suffering from mental health problems are often severely limited in their social and economic functioning. Mental health problems can develop early in life, are frequently chronic in nature, and have an established hereditary component. The extent to which mental illness runs in families could therefore help explain the widely discussed intergenerational transmission of socioeconomic disadvantage. Using data from three generations contained in the 1970 British Cohort Study, we estimate the intergenerational correlation of mental health between mothers, their children, and their grandchildren. We find that the intergenerational correlation in mental health is about 0.2 , and that the probability of feeling depressed is 63 percent higher for children whose mothers reported the same symptom 20 years earlier. Moreover, grandmother and grandchild mental health are strongly correlated, but this relationship appears to work fully through the mental health of the parent. Using grandmother mental health as an instrument for maternal mental health in a model of grandchild mental health confirms the strong intergenerational correlation. We also find that maternal and own mental health are strong predictors of adulthood socioeconomic outcomes. Even after controlling for parental socioeconomic status, own educational attainment, and own mental health (captured in childhood and adulthood), our results suggest that a one standard deviation reduction in maternal mental health reduces household income for their adult offspring by around 2 percent.

JEL Classification: I12, I14, J62

Keywords: intergenerational transmission, mobility, mental health, economic outcomes

Corresponding author:

Michael A. Shields

Department of Economics

University of Melbourne

Australia 3010

E-mail: mshields@unimelb.edu.au 


\section{Introduction}

Economists have documented over many decades the extent to which parent and child outcomes in life are correlated, with particular attention paid to the intergenerational mobility in education, occupation, wages, and family income (see Haveman and Wolfe, 1995; Solon, 1999; and Black and Devereux, 2010, for reviews). While the estimated intergenerational correlation or elasticity is typically sensitive to when in the lifecycle parents' and children's wages and income are measured, the bulk of estimates lie in the range 0.2 to 0.6 , with the correlation being largest in the US and lowest in the Nordic countries. The intergenerational correlation in economic outcomes is also higher between fathers and sons than between fathers and daughters (see, for example, Dearden et al., 1997; Mazumder, 2005; Lee and Solon, 2009; and Black and Devereux, 2011).

Other recent work has focused on intergenerational correlations in IQ, welfare receipt, consumption, attitudes and social behaviour (see Black and Devereux, 2010 for details). Blanden et al. (2007) find that non-cognitive skills, working through educational attainment, are important in explaining the intergenerational persistence in income. Other research has looked at the importance of the intergenerational transmission of personality (see, for example, Osborne Groves, 2005). Some studies used variations in outcomes between twins and other sibling compositions to identify the importance of genetics versus the shared and non-shared environment of children, to better explain sibling and intergenerational correlations in economic outcomes (see, for example, Bjorklund et al., 2006). As Black and Devereux (2010) note, a better understanding of the determinants and dynamics of intergenerational correlations is crucial for advising policy aimed at reducing societal inequalities.

It is now thought that some part of the intergenerational correlation in economic outcomes can be explained by health status running through family generations, capturing genetic and environmental factors, and potential interactions between the two (see, for example, Ahlburg, 1998; Case et al., 2005; Palloni, 2006; Rutter, 2006; Akbulut and Kugler, 2007; Heckman, 2007; Currie, 2009; Pascual and Cantarero, 2009; Coneus and Spiess, 2011). Currie (2011) documents that inequalities in health develop before school age and are even evident at birth. In her review of the literature, Currie (2009) concludes that there is strong evidence that childhood health is related to parental socioeconomic status, and that child health is a significant predictor of adult outcomes. However, given the complex nature of health, and the dynamics at work, she notes that it is hard to establish from these results just how much of the intergenerational transmission of economic status can be accounted for by health.

Perhaps the most reliable research in this respect has focused on intergenerational correlations in birth weight (Emanuel et al., 1992; Conley and Bennett, 2001; Black et al., 2007; Currie and Moretti, 
2007; Royer, 2009; Currie, 2011), an anthropometric measure of health that suffers less from measurement error and recall biases than self-reported measures of health. For instance, Currie and Moretti (2007) estimate an average intergenerational correlation of 0.17 , such that a $100 \mathrm{~g}$ increase in the birth weight of a mother is associated with a $17 \mathrm{~g}$ increase in birth weight of her child. Other studies have looked at the intergenerational correlation in height, weight and BMI (e.g. Akbulut and Kugler, 2007; Whitaker at al., 2010).

Studies have also shown a significant association between various indicators of parental health and their children's health status when measured in childhood (e.g. Case et al., 2002). For example, Coneus and Spiess (2011) show a strong correlation between parental health and various measures of child health at birth and at age two using German data. Using data from the UK, Palloni (2006) finds early-childhood health accounts for around 9 percent of the parent-child correlation in social class.

One pathway for the intergenerational transmission of health is via the transmission of health behaviours such as smoking, drinking or eating patterns, suggesting that children may learn from or copy their parents (e.g. Charles and Hurst, 2003; Loureiro et al., 2006). Göhlmann et al. (2010), for example, estimate using German data that both daughters and sons are between eight and six percentage points more likely, an increase of 40 and 60 percent, respectively, to start smoking if their mother and father have been smokers. Another example in this literature is Schmidt and Tauchman (2011) who identify a strong intergenerational correlation of alcohol consumption between fathers and sons and mothers and daughters at the higher end of the distribution of alcohol consumption of the children, suggesting a large degree of heterogeneity in the transmission mechanism. With respect to a correlation of eating behaviour of parents and their children, Goode et al. (2008) find a strong correlation between mother and daughters only.

In this paper we attempt to contribute to the understanding of the role that health plays in accounting for the persistence of economic outcomes across generations by focusing on mental health within families. Mental health is a major dimension of health, but is a relatively under-researched topic in the intergenerational mobility literature. Mental health disorders have an established hereditary component (see, for example, Abkevich et al., 2003; Dick et al., 2003; Rutter, 2006). Rutter (2006) notes that, "We do not have good genetic evidence on all psychiatric conditions but the available evidence indicates that virtually all psychiatric disorders show a significant genetic contribution to individual differences, with heritabilities at least in the 20 to 50 percentage range" (p. 81). Moreover, mental health disorders are often chronic in nature and have been shown to have a substantial impact on economic outcomes (see Ettner et al., 1997; Hamilton et al., 1997; Marcotte et al., 2000; Alexandre 
and French, 2001; Chatterji et al., 2007; Ojeda et al., 2009; Zhang et al., 2009; and Chatterji et al., 2011). In extreme cases such as schizophrenia, only about one-fifth of people recover or see a marked improvement (Rutter, 2006).

Mental health disorders often start early in life (e.g. Prager, 2009) and reoccur throughout adulthood, and therefore can cast a long shadow over family life (Goodman et al., 2011). Currie et al. (2010) find that early life mental health problems are significantly predictive of adult outcomes even after controlling for future health and health at birth. Fletcher (2009) using US Add Health data finds a strong negative relationship between adolescent depressive symptoms and years of schooling, which is mainly due to an increased likelihood of dropping out of school. Other research has focused on the adverse effect of childhood ADHD on educational outcomes (e.g. Currie and Stabile, 2006; Fletcher and Wolfe, 2008).

Using data from the National Longitudinal Survey of Youth (NLSY), Akbulut and Kugler (2007) estimate that the children of depressed mothers are up to 15 percentage points more likely to be depressed latter on in their life compared to children of non-depressed mothers. Using data from the British Household Panel Study (BHPS), Powdthavee and Vignoles (2008) show a significant relationship between the mental distress of parents and the life satisfaction of their teenage children. Schepman et al. (2011) find that maternal emotional problems have been increasing over time in England, and conclude that this trend helps explain rising adolescent emotional problems. Goodman et al. (2011) using data from the 1958 National Child Development Study (NCDS), find that psychological problems experienced by the age of 16 were associated with a 28 percent lower household income by the age of 50, while the effect of physical health problems was relatively small. Similarly, Smith and Smith (2010) using US data from the PSID find that psychological problems in childhood are associated with a 35 percent reduction in adult family incomes. Overall, therefore, mental health might be a salient factor in explaining the persistence in intergenerational economic outcomes.

In this study we (1) carefully document the extent to which mental health is correlated across three generations in the same family using data from the 1970 British Cohort Study (BCS70), and (2) establish how strongly poor mental health of mother and child is predictive of future economic outcomes (up to age 34). If mental health is strongly correlated across generations and is a substantive predictor of economic outcomes, then this is consistent with the hypothesis that mental health is one of the key pathways explaining the intergenerational correlation of economic outcomes. In this respect, a strong feature of the BCS70 data is that it does not rely on recall or proxy information to measure past 
mental health. The same set of questions identifying mental health was administered to both the mother and her cohort child (when an adult) on three separate occasions, at roughly the same points in the lifecycle. ${ }^{1}$ We also have data on an indicator of early mental health problems of a reasonable sample of grandchildren (children of the cohort members), allowing a novel investigation of mobility across more than two generations and the use of an instrumental variables approach to address concerns of unobservable family heterogeneity.

\section{Data}

\subsection{The 1970 British Cohort Study}

The data we use are drawn from the 1970 British Cohort Study (BCS70). The BCS70 was initiated by the National Birthday Trust Fund and the Royal College of Obstetricians and Gynaecologists, and began with an at-birth survey of around 17,000 people born between April 5-11 1970 in England, Scotland, Wales and Northern Ireland (overall catchment was estimated at 95 to 98 percent of all births). Originally designed to study perinatal mortality and the provision of ante- and post-natal services (Chamberlain, 1975), the BCS70 was subsequently expanded and now includes seven major follow-up surveys - 1975, 1980, 1986, 1996, 2000, 2004 and 2008. The three major childhood surveys (age 5, 10 and 16) include, in addition to the original birth cohort, any children who were born outside of the country during the reference week but who were identified from school registers at later ages. These childhood surveys collected detailed information from parents (mostly the child's mother) on the cohort member's health and behaviour, and on family demographics and socioeconomic status. Cognitive ability was also assessed in these surveys via a range of tests administered by the survey interviewers. In the age 10 and age 16 surveys, additional information was collected from teachers regarding each participant's academic achievements or difficulties, and from the community medical officer who conducted a comprehensive medical evaluation. The four major adult surveys collected information from the cohort member on employment, income, education, health, relationships and attitudes.

\subsection{Mental health index}

Mental health is measured using nine of the original 24 questions of the Rutter Malaise Inventory administered to mothers in 1975, 1980 and 1986, and to their children (the cohort member) in 1996, 2000 and 2004 (see Table 1). Mental health information was not collected in any survey year from

${ }^{1}$ Recently Mare (2011) stressed the need to consider multigenerational effects when investigating intergenerational mobility. 
cohort members' fathers. The 24-item Malaise Inventory developed by Rutter et al. (1970) is a short version of the 196-item Cornell Medical Index of Health questionnaire and its contents have been widely validated to be accurate in identifying symptoms of anxiety and depression (McGee et al., 1986; Grant et al., 1990; Rodger et al., 1999). These mental health questions are similar in content to and correlate strongly with the items contained in the General Health Questionnaire (GHQ12) and in the Kessler Psychological Distress Scale (K10). ${ }^{2}$ In the 1975, 1996, 2000 and 2004 surveys, respondents could answer each mental health question with no (0) or yes (1). In the 1980 survey the responses are coded anywhere between 0 (seldom or never) and 1 (most of the time), and in 1986 the responses are coded as 0 (rarely or never), 0.5 (some of the time) or 1 (most of the time). Table 1 reports for each item separately, the sample average of answers for mothers and their children.

Our mental health indices are created by first averaging the nine responses in each year to create yearly mental health indices (1975, 1980 and 1986 for mothers, and 1996, 2000 and 2004 for children), and then averaging the indices across years. Given that these constructed mental health indices have no easily interpretable units, we further standardise them such that each has a mean of zero and a standard deviation of one, with larger values signifying worse mental health. Not all cohort members are surveyed in 1996, 2000 and 2004, and not all of the cohort members who are, have a mother surveyed in 1975, 1980 and 1986 (the response rate was especially low in 1986 when a teacher-led industrial dispute disrupted the dissemination of the BCS70 questionnaire). To balance our approach of averaging mental health against the need to maintain sufficient sample size, we restrict the sample to include those mothers and children who each complete at least two surveys. This restriction reduces the sample size to 8,496 cohort members. Another 302 observations are lost due to missing information for child and family characteristics collected in 1970 and 1975, leaving an estimation sample of 8,194 cohort members, of which 4,345 are female and 3,849 are male. ${ }^{3}$

The advantage of averaging health responses across three surveys is that it helps to reduce measurement error. Estimation bias created by measurement error is one of the most important empirical issues in the income mobility literature, with a number of studies documenting substantial attenuation of estimated mobility parameters (e.g. Mazumder, 2005). In this literature the most

\footnotetext{
${ }^{2}$ The cohort members are given the General Health Questionnaire in the 2000 BCS70 survey and four questions from the Kessler Psychological Distress Scale in the 2004 BCS70 survey. The correlations between our cohort member mental health index and indices created from the GHQ and K10 items equal 0.54 and 0.63 , respectively.

${ }^{3}$ To investigate the role of attrition, we compared the intergenerational correlation between cohort member mental health in 2000 and maternal mental health in 1975, for those in the sample (mother and child with at least two completed surveys each) and those not in the sample (mother and child with less than 2 completed surveys each). The estimated correlations were not significantly different from one another, indicating that the correlation is not larger for the more strongly "attached" survey respondents. Though this evidence is obviously limited, it suggests that attrition is unlikely to be severely biasing our results.
} 
common method for reducing attenuation bias is to average income over a number of years, preferably when parents and children are aged in their 30s and 40s. Equivalently, if health measurements from individual survey years suffer from transitory shocks - due to, for example, short-term illness or reporting error - the ensuing attenuation bias can be reduced by averaging health measures over a number of time periods.

Another important advantage of the BCS70 data is that mental health is measured for mothers and their children at similar ages: average age of mothers is 35.7, and the average age of their children is 30.3. Due to data limitations, other similar studies have measured child health at a much younger age than parental health, or must rely on retrospective reports of parental health - for example, in Pascual and Cantarero's (2009) study of the intergenerational mobility in general health, the mean age for sons is 24 , while the mean age for fathers is 55 . Given the variation in individual health over time, a significant misalignment in the age of paternal and child health measurement may cause a type of lifecycle bias (for a discussion, see Black and Devereux, 2011). Similarly, child reports of their parents' past health are likely to suffer from substantial recall bias.

The raw relationship between cohort members' mental health and their mothers' mental health is presented in Figure 1, with each dot representing 50 mother-child pairs. The scatter plot indicates that a strong positive relationship exists in mental health across generations, and that the intergenerational correlation is approximately 0.19; given the standardisation of mental health measures, this implies that a one standard deviation increase in maternal mental health increases child mental health by 0.19 standard deviations. ${ }^{4}$ Figure 1 also shows that the relationship is approximately linear for maternal mental health values up to around 2, which represents 95 percent of observations. This feature justifies the linearity assumption imposed in subsequent regression analyses. Values of maternal mental health above 2 are rare, but when such severe mental health problems occur, Figure 1 suggests that child mental health is also particularly poor.

In addition to information on the mental health of cohort members and their mothers, the BCS70 contains information on the mental health of cohort members' children (i.e. the mothers' grandchildren). In 2004 only, the BCS70 collected additional information from a one-in-two sample of cohort members who had children. Information was collected about all the children of the sampled cohort members via an interview and self-completion questionnaire given to the cohort members, and from self-completion questionnaires given to older children (aged 10-17). Included in the cohort member self-completion questionnaire was the Strengths and Difficulties Questionnaire (SDQ). The

\footnotetext{
${ }^{4}$ Our indicator of mental health is increasing in mental health problems and, therefore, worsening mental health. For ease of exposition, however, we interpret the intergenerational correlation coefficient in terms of increases in mental health.
} 
SDQ is a 25 -item instrument for assessing social, emotional and behavioural functioning, and has become the most widely used research instrument related to the mental health of children. The SDQ questions cover positive and negative attributes and respondents answer each with a response "not true" (0), "somewhat true" (1), or "certainly true" (2). One example of an item capturing emotional problems is "Is often unhappy, down-hearted or tearful". In our empirical analyses we construct a measure of grandchild mental health by summing the responses to the five conduct-disorder items, five emotionalproblem items, five hyperactivity items, and five peer-problem items. The total scores were then standardised to mean zero and standard deviation one, where a higher score implies more mental health problems. ${ }^{5}$ In the data there are 1,403 cohort members with 2,265 children for whom complete health information is available for all three generations. For this sub-sample in 2004, the cohort members' mothers were on average 60 years of age, the cohort members were 34 years of age, and the cohort members' children ranged in age from four to 16 and were on average eight years of age.

The relationships between cohort members' and their mothers' mental health and the mental health of cohort members' children is illustrated in Figure 2. Immediately clear from the nonparametric regression estimates is that the relationship between the mental health of mothers (female cohort members) and their children (correlation coefficient of 0.37) is much stronger than the relationship between the mental health of fathers (male cohort members) and their children (correlation coefficient of 0.22). Figure 2 also shows that the mental health of grandmothers (cohort member mothers) is positively related to the mental health of their grandchildren (correlation coefficient of 0.12). In the following sections we investigate whether this positive "grandmother effect" flows entirely through the effect of grandmothers' mental health on their own children's mental health, or directly on their grandchildren's mental health.

\subsection{Control variables}

The variables used as controls in the regression analyses are listed in Table 2. These variables are used to capture any childhood circumstances that may have jointly affected both maternal mental health and own mental health later in life. Apart from gender, the control variables are divided into six categories: (1) "childhood health in 1970" includes measures of at-birth health outcomes such as birth weight and congenital abnormalities; (2) "family characteristics in 1975" includes measures of socioeconomic status, such as mother's age at birth, mother's education and father's social class; (3) "childhood health in 1975 " includes indicators for whether the child has a health problem and whether the child had an

\footnotetext{
${ }^{5}$ The non-standardised SDQ score in our data ranges from 0 to 35 , the median equals 7 , the mean equals 7.95 , and the standard deviation equals 5.48 .
} 
accident requiring medical attention; (4) "childhood test scores in 1975" includes three measures of early childhood cognitive ability; (5) "childhood mental health in 1975" is measured using the Rutter behavioural problems index, which is similar to the Strengths and Difficulties Questionnaire; and (6) "adult physical health in $2000 "$ includes ten indicators of chronic illnesses.

\section{Modelling approach and results}

\subsection{Intergenerational correlation in mental health}

The relationship between the mental health (averaged over 1996, 2000 and 2004; at average age of 30) of the cohort member $\left(H_{i}^{C}\right)$ and their mother's (averaged over 1975, 1980 and 1986; at average age of 36) mental health $\left(H_{i}^{M}\right)$, is modelled using linear regression:

$$
H_{i}^{C}=\alpha_{1}+\alpha_{2} H_{i}^{M}+X_{i}^{C \prime} \beta_{1}+X_{i}^{M \prime} \beta_{2}+\varepsilon_{i}
$$

where the mental health measures are standardised to mean zero and standard deviation one, such that the coefficient $\alpha_{2}$ in equation (1) can be interpreted as a standard deviation change in $H_{i}^{C}$ due to a standard deviation change in $H_{i}^{M}$. The vector $X_{i}^{C}$ captures cohort member characteristics, and vector $X_{i}^{M}$ captures parental characteristics. Our empirical strategy is to sequentially estimate increasingly richer variants of equation (1) in order to test the robustness of our results: Model (1) includes only maternal mental health as a covariate; Model (2) adds gender and cohort member health information measured in 1970; Model (3) adds socioeconomic status of the parents measured in 1975; Model (4) adds cohort member health information measured in 1975; Model (5) adds measures of cognitive ability of the cohort member in 1975; Model (6) adds cohort member mental health measured in 1975; and Model (7) adds cohort member physical health measured in 2000. The estimated correlations between maternal and child mental health $\left(\hat{\alpha}_{2}\right)$ for each model variant are reported in Table 3 . The estimates of the intergenerational correlation between mothers' and children's mental health problems are significant at the 1 percent level in all model specifications.

The estimate of the intergenerational correlation in mental health obtained from Model (1) equals 0.190 . In other words, a one standard deviation increase in the average mental health of mothers is associated with a 0.190 standard deviation increase in the average mental health of their children some 20 years later. Controlling for gender and at-birth health information decreases the estimate slightly to 0.182 , and further controlling for parental socioeconomic status (SES) when the child was aged five further reduces the estimate to 0.170 . The drop in the maternal mental health effect after 
controlling for traditional measures of parental SES suggests that SES may be a partial trigger of maternal mental health problems and subsequent cohort member adult outcomes. ${ }^{6}$ The estimated correlation coefficient, once controlling for child health at age five (Model (4)), and additionally for child test scores (Model (5)), are only slightly smaller at 0.168 and 0.163 , respectively. Model (5) is our preferred specification as it controls for some of the potential determinants of maternal mental health in 1975. We note that the R-squared values for these models range from 4 percent to 8 percent, implying that there remains a sizeable proportion of unexplained heterogeneity in adulthood mental health. The full set of estimates for Model 5 is shown in the Appendix Table A1.

In Models (6) and (7) we additionally include control variables that might have been caused to some extent by maternal mental health problems - namely, age five mental health problems, and physical health problems of the cohort member experienced at age 30. The estimated mental health correlation coefficient obtained from Model (6) equals 0.145, suggesting that the significant effects observed in Models (1) to (5) are unlikely to be the consequence of childhood mental health problems determining both maternal and adult mental health problems. Model (6) does not, however, exclude the possibility that maternal mental health problems are caused by maternal physical health problems. If the cohort member inherits a susceptibility to physical health problems, then the intergenerational mental health effect could be caused by physical health problems that are similar amongst mothers and their children. We have no data on maternal physical health in 1975, however, controlling for cohort members' physical health at age 30 in Model (7) does not substantially change our main result (0.133).

\subsection{Subgroup Analyses}

A common finding amongst studies on the intergenerational transmission of economic outcomes is that the transmission is typically strongest between mothers and daughters, and between fathers and sons. If this is also the case for mental health, then we would expect the correlation between maternal and child mental health to be larger for the female line than for mother-son comparisons. Using the Model (5) specification, we do find that the estimated mental health correlation for mothers-daughters is about 30 percent $(0.177)$ larger than for mothers-sons $(0.143)$ - see row 1 of Table 4 . However, these two estimates are not significantly different with a $p$-value of 0.166 .

A potentially important difference between the cohort members and their mothers is that not all cohort members have at least one child. To investigate the effect of this difference, we restrict the sample to cohort members who have at least one child by age 30 . The estimated mental health

\footnotetext{
${ }^{6}$ An explanation for the link between parental SES and child mental health problems is that low SES is correlated with poor parenting outcomes, which can affect children's mental wellbeing (e.g. Harris and Marmer, 1996).
} 
correlation shown in row 2 of Table 4 is roughly the same at 0.161 for those without a child compared to 0.163 for the full sample. However, the estimate is about 20 percent lower for mothers-sons $(0.116$ compared to 0.143 for the full sample), whereas no such difference is evident for the mother-daughter relationship (0.181 compared to 0.177$)$.

We also test whether the correlation between mothers' average mental health and that of her child differs depending upon whether or not the cohort members as adults (at average age 30) were in regular contact with their mother in year 2000 (at average age around 60). We might expect the intergenerational correlation to be larger for those in regular contact because of possible cumulative exposure effects over time. The results are shown in row 3 of Table 4, and are consistent with this hypothesis for daughters. For daughters who report to rarely or never see their mothers the size of the correlation coefficient in mental health is smaller than for the full sample (0.177 compared to 0.146$)$. In contrast, the mother-son correlation coefficient in mental health remains unchanged ( 0.143 compared to $0.141)$.

\subsection{Alternative outcome measures}

So far we have focused on the intergenerational correlation using our continuous mental health index. Additional insight can be gained from looking specifically at poor levels of mental health across generations. Row 4 of Table 4 provides estimated marginal effects from a binary probit model where both mothers' and children's mental health is defined as poor $(=1)$ if their respective average mental health scores are equal to or greater than plus one standard deviation ( $=0$ otherwise). This represents roughly the worse 15 percent of mental health scores for both mothers and children. The resulting estimates are substantial with an increase in the probability of having poor mental health for cohort members who had a mother in poor mental health of 9.2 percentage points, or 60 percent relative to the sample mean, for the full sample. The predicted increase is higher for mothers-daughters (11 percentage points) than mothers-sons (7 percentage points), which is consistent with our previous findings using the continuous mental health index.

Finally, we focus on specific dimensions of mental health available from the nine questions used to derive the mental health index that have been consistently administered to both parents and cohort members (see Table 1 for item questions and sample proportions). On the basis of the set of covariates used in Model (5), a separate binary probit model is estimated for each binary mental health symptom listed in Table 1. The estimated intergenerational marginal probabilities range between 0.175 and 0.093 and are each statistically significant at the 1 percent level. The effects are highest for the 
symptoms "Do you feel tired most of the time?" (0.175), "Do you often feel miserable or depressed?" (0.169) and "Are you easily upset or irritated?" (0.157), and lowest for the symptoms "Are you constantly keyed up and jittery?" (0.113), "Does your heart often race like mad" (0.110) and "Does every little thing get on your nerves and wear you out?" (0.093). We can interpret these marginal probability effects as follows: for example, a child whose mother reported having often felt miserable or depressed is 16.9 percentage points, or about 63 percent relative to the mean value, more likely to experience the same symptom in adulthood than a child whose mother did not report this symptom.

Overall, the strong and statistically significant intergenerational correlation in mental health between mother and child is robust to various sub-samples and alternative measures of poor mental health.

\subsection{Age of exposure to maternal mental health problems}

The analysis, so far, has concentrated on estimating the relationship between the maternal and child's mental health evaluated at averages of mental health that stretch over a horizon of approximately ten years for both mothers (1975-1986) and their children (1996-2004). However, the intergenerational correlation may vary depending upon the cohort member's age at which he or she was exposed to a given level of maternal mental health problems. Moreover, a cohort member exposed to maternal mental health problems throughout childhood may have different adult mental health than a cohort member exposed only in one particular observation period (1975, 1980 or 1986). To identify these dynamic effects, we estimate the following model, in which each of the maternal mental health observation may yield a separate effect on the child's average mental health:

$$
H_{i}^{C}=\alpha_{1}+\alpha_{2} H_{i, 75}^{M}+\alpha_{3} H_{i, 80}^{M}+\alpha_{4} H_{i, 86}^{M}+X_{i}^{C \prime} \beta_{1}+X_{i}^{M \prime} \beta_{2}+\varepsilon_{i}
$$

We start by adding the maternal mental health measures incrementally. Including only $H_{i, 75}^{M}$ the estimate of the intergenerational correlation $\left(\alpha_{2}\right)$ is 0.119 ; including only $H_{i, 80}^{M}$ the correlation $\left(\alpha_{3}\right)$ is 0.138 ; and including only $H_{i, 86}^{M}$ the correlation $\left(\alpha_{4}\right)$ is 0.152 . Each is significant at the 1 percent level. As expected, these correlations are lower than our main estimate based on the average maternal health score, and suggest that the intergenerational correlation grows stronger as the child becomes older (the $t$-stat on the difference between $\alpha_{2}$ and $\alpha_{4}$ is 2.6). When all three measures of maternal mental health are included simultaneously in the model the estimates are $0.035,0.066$ and 0.110 , respectively. Summing these three estimates suggests that an increase in mother's mental health by one standard 
deviation throughout childhood (at ages five, ten, and 16) increases the cohort member's average mental health by 0.212 of a standard deviation $(t$-stat $=11.47)$.

\section{Mental health across three generations}

The preceding analysis has shown that mothers' mental health is significantly correlated with their children's mental health in adulthood, and that this intergenerational relationship is stronger for mother-daughter than mother-son comparisons. Given the long time span of the BCS70 and data availability on grandchildren, we test whether mothers' mental health is correlated not only with their children's, but also with their grandchildren's mental health. By comparing cohort members' mental health with their own children's mental health, we are also able to separate out the strength of the intergenerational correlation coefficient between mother-daughter and father-son comparisons. Moreover, due to the availability of data on the third generation, we can estimate a causal effect of parents' mental health on their children's mental health by instrumenting parent (cohort member) mental health with grandmother (cohort member mother) mental health in a 2SLS approach. ${ }^{7}$

In column (1) of Table 5, we report the effect of grandmothers' mental health problems on grandchildren's mental health controlling for grandchildren's age and gender in addition to the control variables used in our preferred specification of Model (5) in Table 3. Despite controlling for the grandparents' SES and the parents' cognitive ability and physical health, grandmother mental health is significantly related to grandchild mental health: a one standard deviation increase in grandmother average mental health increases grandchild mental health by 0.090 standard deviations. Interestingly, this strong and significant relationship is unchanged (0.086) when parent (cohort member) controls from 2000 (education, marital status, household size, income) are added (see column 2), suggesting that the effect from grandmother to grandchild does not run through parent (cohort member) SES. The grandmother effect is no longer significant, however, once parent (cohort member) mental health is included in the model: a one standard deviation increase in parent mental health is estimated to increase the child's mental health by 0.305 standard deviations (see column 3).

Mental health measurements from three generations provide the opportunity to estimate the causal effect of parental mental health on child mental health. While we cannot test the absolute validity of this approach, the results we presented above are suggestive that the impact of grandmothers' mental health on grandchild mental health works solely through increasing the probability that her child

\footnotetext{
${ }^{7}$ A number of previous studies have used grandparent outcomes as instruments in models of third-generation outcomes. For instance, grandparents' SES has been used as an instrument for parent's SES when estimating the relationship of welfare dependency between parents and their children (e.g. Cobb-Clark et al., forthcoming; Maurin, 2002).
} 
(the parent of the grandchild) reports poor mental health. We therefore use the mental health of cohort members' mothers $\left(H_{i}^{M}\right)$ measured in 1975-1986 as an instrumental variable for the mental health of cohort members $\left(H_{i}^{C}\right)$ measured in 1996-2004, in a 2SLS model that explains the mental health of cohort members' children $\left(H_{i}^{G C}\right)$ measured in 2004:

$$
\begin{aligned}
& H_{i}^{C}=\alpha_{11}+\alpha_{21} H_{i}^{M}+X_{i}^{G C \prime} \beta_{11}+X_{i}^{C \prime} \beta_{21}+X_{i}^{M \prime} \beta_{31}+u_{i 1}, \\
& H_{i}^{G C}=\alpha_{12}+\alpha_{22} H_{i}^{C}+X_{i}^{G C \prime} \beta_{12}+X_{i}^{C \prime} \beta_{22}+X_{i}^{M \prime} \beta_{32}+u_{i 2},
\end{aligned}
$$

where equation (3) is the first-stage that instruments the potentially endogenous mental health of cohort members $H_{i}^{C}$ with grandparents' mental health $H_{i}^{M}$. Equation (4) is the second-stage or main outcome equation that estimates the effect of $H_{i}^{C}$ as the main variable of interest to explain grandchildren's mental health $H_{i}^{G C}$. This approach is similar to Loureiro et al. (2010) who use 2SLS to estimate the intergenerational transmission of smoking. The important difference between Loureiro et al. (2010) and our approach is that we have the same outcome measures available for parents and grandparents (measured approximately 20 years apart), whereas Loureiro et al. (2010) instrument parental smoking with grandparents' SES. Moreover, we include an extensive set of grandparent control variables (including grandparent SES).

The estimation results are shown in column 5 of Table 5. The 2SLS estimate of $\alpha_{22}$ is equal to 0.480 , which means that a one standard deviation increase in parental mental health is estimated to increase child mental health by nearly one-half of a standard deviation. ${ }^{8}$ However, the 2SLS estimate is not significantly different from the OLS estimate of 0.310 presented in column (4). ${ }^{9}$

Our main analysis of the parent and child mental health relationship focuses exclusively on the correlation between mother and child, as we do not have information on the mental health of cohort members' fathers. However, we can use the data on cohort members and their children to test if there is a difference in the magnitude of the intergenerational correlation working through the maternal and paternal lines. The results, presented in Table 6, show that for female cohort members the effect of grandmother mental health on grandchild mental health is 0.103 , and is little changed by including

\footnotetext{
${ }^{8}$ Obtaining a 2SLS estimate that is larger than the corresponding OLS estimate is common in the intergenerational income mobility literature - see for instance Dearden et al. (2007). The typical explanation is that instrumenting the parental outcome reduces attenuation bias and hence increases the estimated intergenerational effect.

${ }^{9}$ The first stage $F$-test statistic of grandparent mental health equals 27.98 , which is substantially larger than the commonly applied weak instrument cut-off value of 10 .
} 
parent (cohort member) controls from 2000 (0.100). The grandmother effect is almost one-third of the size of the effect of mother's (female cohort members) mental health on her own child's mental health (0.340; see column 4). This suggests that the intergenerational transmission of mental health from daughter to daughter to daughter is strong. The estimated effect of female cohort member mental health on their child's mental health equals 0.340 from the OLS model (column 4) and 0.503 from the 2SLS model (column 5). ${ }^{10}$

The results for male cohort members in Table 6 show that the transmission of mental health from fathers (male cohort members) is weaker than the transmission from mothers to their children. The estimated effect of paternal mental health problems equals 0.226 (column 4), which is around twothirds the size of the maternal mental health effect (0.340). Also, the mental health of grandmothers has no statistically significant effect on the children of the male cohort members, and is only half the size of the otherwise significant effect of grandmothers on the children of the female cohort members (0.048 versus 0.103$)$.

\section{The economic costs of maternal and own mental health problems}

In this section we ask whether the strong intergenerational transmission of mental health problems, which we have documented across three generations, matters in determining key indicators of adulthood economic success. If this is the case, then our findings on the strong persistence of mental health problems within families lend support to the hypothesis that mental health is an important mechanism by which economic outcomes are transmitted across generations in the same family. Three adult economic outcomes are considered: (1) a binary indicator of whether the cohort member has a degree level qualification by age 30; (2) average self-reported financial wellbeing recorded in 2000 (age 30) and 2004 (age 34) that is coded on a five-point scale from 1 (finding it very difficult to manage financially) to 5 (living comfortably); and (3) average household income (logarithm) recorded at age 30 and 34 (pooled). In addition to assessing the predictive power of maternal, and cohort member's mental health (at age 26-34) we also control for an earlier measure of the cohort member's mental health measured at age ten. ${ }^{11}$

\footnotetext{
${ }^{10}$ The $F$-test statistic of the first stage instrument equals 23.95 for mothers and 12.95 for fathers.

${ }^{11}$ We create a standardised index from a range of questions administered on the mother, in which she was asked to judge to what degree a specific statement relates to their child (i.e. "Doesn't apply", "Applied somewhat", and "Certainly applies"). Examples of these are: "Often destroys own or others belongings", 'Often worried, worries about many things", 'Is often disobedient", "Often tells lies", "Bullies other children" and is "Very restless, often running about or jumping up and down, hardly ever still".
} 
Parameters of interest are presented in Table 7, and the full set of estimates for the final specification (columns 2, 6 and 10) for each economic outcome is provided in Appendix Table A2. Estimates of the effects of mental health on education outcomes are interpreted as the marginal probability effects obtained from binary probit models (columns 1 and 2). Estimates of the effects of mental health on self-reported financial wellbeing and household income are interpreted as one unit increases in financial wellbeing and percent increases in household income obtained from linear regression models (columns 3 to 10). Each model controls for the Model 5 set of covariates (see Table 2).

As interesting points of comparison, we also provide in the table the estimates for higher maternal education $(0,1)$, father's social class (unskilled) when the cohort member was age five $(0,1)$, father figure was absent from the household when the cohort member was age five $(0,1)$, and two measures of early childhood cognitive ability (vocabulary and copying tests) collected at age five (mean zero, standard deviation one). In the models presented in columns 6 and 10, we additionally control for whether the cohort member obtained a degree-level qualification by age 30, to assess whether the effect of poor maternal mental health works through lowering the probability that the child obtained a degree-level education, or whether the significant negative association of poor maternal mental health on the economic outcomes of their children remains over-and-above the educational attainment pathway.

Mothers' mental health is a strong and significant predictor of their children's human capital accumulation. A one standard deviation worsening of mothers' mental health is associated with a 1.4 percentage point lower probability of their children gaining a degree by age 30 (column 1). Adding an indicator of the child's own mental health at age ten (column 2) halves the size of the estimate for maternal mental health and renders it to be statistically insignificant. The predictive effect of a one standard deviation improvement in mental health (0.023) is around one-tenth of the positive effect of having a mother with a high level of education, which is defined as having more than three years of full-time education after the minimum school leaving age (0.229). It is also about one-half of the positive effect of early measures of cognitive ability measured at age five (0.039 and 0.061).

Poor maternal mental health is predicted to significantly worsen financial satisfaction as reported by the offspring in adulthood (columns 3-6), which remains significant even after controlling for the child's mental health measured at age ten and in adulthood (age 26-34) and the cohort member's education level. Human capital and mental health impact equally strongly on contemporaneous financial wellbeing. For instance, if the cohort member has a degree-level 
qualification at age 30 , it increases financial wellbeing by 0.245 units on a scale from one to five, whereas a standard deviation increase in mental health problems in adulthood decreases financial wellbeing by -0.224 units.

Similar patterns emerge when predicting household income of cohort members at ages 30 and 34. A one standard deviation increase in maternal mental health problems is associated with a 3.6 percent reduction in household income of the children in adulthood, which is equivalent to about onethird of the effect of mothers' (high) education level (10.8 percent). Although the effect of mothers' mental health is reduced by about 30 percent to -0.021 when controlling for the cohort members' mental health at age ten and in adulthood, ${ }^{12}$ and educational qualification, it is still statistically significant and is equivalent to one-quarter of the effect of the child's adulthood mental health on household income (-8.3 percent).

Finally, we re-estimated all models by additionally controlling for the physical health of the cohort member at age 30 (items are listed in Table 2). As argued in Section 3.1, poor physical health could give rise to pain, anxiety and depression, and therefore to a high score on the mental health problems index. However, the strong predictive power of both maternal and cohort members' mental health in key economic outcomes remains unchanged. For example, the estimated coefficient for maternal mental health in the subjective wellbeing and household income models is $-0.017(t$-stat $=-1.84)$ and $-0.021(t$-stat=-2.53), respectively.

\section{Conclusion}

Poor mental health weighs heavily on families, and can cast a long shadow over family life (Goodman et al., 2011). Symptoms of depression and anxiety, for instance, are associated with severe limitations in economic and social functioning. Often, they start early in life, and hinder human capital formation in adolescence and early adulthood. Given the chronic nature and the established hereditary component of many mental health conditions, the transmission of mental health across generations is one potential mechanism by which socioeconomic disadvantage is passed on across generations of the same family. In this paper, we contribute to the literature on the intergenerational transmission of social inequalities by quantifying the strength of the correlation of mental health problems between three generations and assessing the long-term economic costs associated with mental health problems. The analysis is

\footnotetext{
${ }^{12}$ If we dropped average maternal mental health from Model (8), then the estimate of the effect of childhood mental health (measured at age ten) household income is statistically significant and has a coefficient of $-0.0192(\mathrm{t}-\mathrm{stat}=-2.43)$.
} 
conducted with a unique British cohort study (1970 British Cohort Study) that allows us to minimise potential sources of measurement error and lifecycle bias.

We estimate an intergenerational correlation coefficient in mental health of 0.190 , which means that a one standard deviation decrease in maternal mental health (measured when the cohort member was a child) is associated with a 0.19 standard deviation decrease in the child's mental health some 20 years later. The size of this correlation coefficient is similar to the estimated intergenerational transmission of income (e.g. Dearden et al., 1997) and birth-weight (e.g. Currie and Almond, 2007). Additionally controlling for at-birth health information reduces this correlation to 0.182 , and it is further reduced to 0.170 when parental socioeconomic status controls are added to the model. Even after controlling for child health at age five, child cognitive test scores and physical health conditions, we are left with a strong and significant intergenerational correlation in mental health (0.133). We also find evidence that this intergenerational correlation is about 30 percent larger for mother-daughter than for mother-son comparisons. Our results also suggest that the strength of the correlation in mental health between mother and child increases with the age at which the child was exposed to episodes of maternal mental health problems. These results are robust to a variety of sample restrictions and alternative definitions of mental health problems. For example, we find that a mother who reported that she often felt miserable and depressed is associated with an increase in the probability of her child having the same problem as an adult by about 63 percent relative to the sample average.

The long time horizon of the 1970 British Cohort Study allowed us not only to investigate the magnitude of the correlation coefficient of mental health problems across three generations (grandmother, parent, grandchild), but also to separate out the gender differences in this transmission. We estimate a strong and significant correlation coefficient of mental health problems between grandmothers and their grandchildren, where a one standard deviation increase in grandmother mental health is associated with a change in grandchild mental health of 0.09 standard deviations. This association persists even after controlling for a wide range of grandparental and parental health and socioeconomic characteristics, but disappears when controlling for the parent's mental health. On the basis of this latter finding, a 2SLS approach is motivated that uses grandmother mental health as an instrument for parent mental health in a model that attempts to explain grandchildren's mental health. The results from this model confirm the strong association in mental health across generations, and provide some evidence to suggest that this relationship is likely to be causal in nature rather than spuriously determined by unobserved family heterogeneity. We also find that the intergenerational correlation in mental health is stronger through the maternal than the paternal line by about 50 percent. 
The persistence of mental health problems should interest economists in so far as we were able to show that the experience of mental health problems and the exposure to maternal mental health problems at various stages in the lifecycle of an individual, are predictive of adult economic outcomes. This powerful result suggests that mental health is passed on through generations and is likely to be an important element in explaining the persistence of economic outcomes across family generations. Having a mother in poor mental health is a significant predictor of whether her child obtains a degreelevel qualification, is satisfied with his or her own financial situation and how much household income her child will have in adulthood. The effects are considerable, even when controlling for the offspring's own mental health experienced as adults. For instance, a one standard deviation decline in the mother's mental health reduces the child's household income at ages 30 to 34 by more than two percent. This effect is about a quarter of the cohort member's own mental health measured in adulthood.

We finish by noting three key caveats of this study. Firstly, the 1970 British Cohort Study does not contain data on clinical diagnosis of mental health conditions; rather we have focused on intergenerational correlations in self-reported indicators of symptoms of mental health problems. Secondly, given the time-span of the data, attrition is likely to affect our sample. If attrition is systematic the estimates of the intergenerational correlation coefficient of mental health problems would be biased of unknown sign and magnitude. Thirdly, while attempting to outline some pathways by which maternal mental health might impact on children's mental health, and consequently their economic outcomes, we could not quantify the genetic component of the intergenerational transmission of mental health problems. However, we believe that the results in this paper help to further progress the growing economics literature on the potentially high social and economic costs of poor mental health.

\section{References}

Akbulut, M., Kugler, A., 2007. Inter-generational transmission of health status in the US among natives and immigrants. Mimeo (University of Texas).

Abkevich, V. et al., 2003. Predisposition locus for major depression at chromosome 12q22-12q23.2. American Journal of Human Genetics 73, 1271-1281.

Ahlburg, D., 1998. Intergenerational transmission of health. American Economic Review Papers and Proceedings 88, 265-270.

Behrman, J., Pollak, R., Taubman, P., 1995. From parent to child. Chicago: University of Chicago Press. 
Black, S.E., Devereux, P.J., 2011. Recent developments in intergenerational mobility, In: Orley Ashenfelter and David Card, Editor(s), Handbook of Labor Economics, Elsevier, 2011, Volume 4, Part 2, Handbooks in Economics - Handbook of Labor Economics, Vol 4B, Pages 1487-1541.

Black, S.E., Devereux, P.J., Salvanes, K.G., 2005. Why the apple doesn't fall far: Understanding intergenerational transmission of human capital. American Economic Review 95, 437-449.

Black, S.E., Devereux, P.J., Salvanes, K.G., 2005. Like father, like son? A note on the intergenerational transmission of IQ scores. Economics Letters 105, 138-140.

Blanden, J., Gregg, P., Macmillan, L., 2007. Accounting for intergenerational income persistence: noncognitive skills, ability, and education. Economic Journal 117, C43-C60.

Bjorklund, A., Lindahl, M., Plug, E., 2006. The origins of intergenerational associations: lessons from Swedish adoption data. Quarterly Journal of Economics CXXI, 999-1028.

Case, A., Fertig, A., Paxson, C., 2005. The lasting impact of childhood health and circumstance. Journal of Health Economics 24, 365-389.

Chamberlain, G., et al. 1975. British births 1970, London: Heinemann.

Charles, K., Hurst, E., 2003. The correlation of wealth across generations. Journal of Political Economy $111,1155-1182$.

Chatterji, P., Alegria, M., Lu, M., Takeuchi D., 2007. Psychiatric disorders and labor market outcomes: Evidence from the National Latino and Asian American Study. Health Economics 16, 1069-1090.

Chatterji, P., Alegria, M., Takeuchi, D., 2011. Psychiatric disorders and labor market outcomes: Evidence from the National Comorbidity Survey-Replication. Journal of Health Economics, In press.

Cobb-Clark, D., Ryan, C., Sartbayeva, forthcoming. Taking chances: The effect of growing up on welfare on the risky behavior of young people. Scandinavian Journal of Economics.

Coneus, K., Spiess, C.K., 2011. The intergenerational transmission of health in early childhood-Evidence from the German Socio-Economic Panel Study. Economics and Human Biology, In Press.

Conley, D., Bennett, N.G., 2001. Birth weight and income: Interactions across generations. Journal of Health and Social Behavior 42, 450-465.

Currie, J., 2009. Healthy, Wealthy, and Wise: Socioeconomic status, poor health in childhood, and human capital development. Journal of Economic Literature 47, 87-122.

Currie, J., Stabile, M., Manivong, P., Roos, L.L., 2010. Child health and young adult outcomes, Journal of Human Resources 45, 517-548.

Currie, J., Moretti, E., 2007. Biology as destiny? Short- and long-run determinants of intergenerational transmission of birth weight. Journal of Labor Economics 25, 231-263. 
Currie, J., Stabile, M., 2006. Child mental health and human capital accumulation: The case of ADHD. Journal of Health Economics 25, 1094-1118.

Dearden, L., Machin, S., Reed, H., 1997. Intergenerational mobility in Britain. Economic Journal 107, 47-66.

Dick, D. et al., 2003. Genome-wide linkage analyses of bipolar disorder: A new sample of 250 pedigrees from the National Institute of Mental Health Genetics Initiative. American Journal of Human Genetics 73, 107-114.

Emanuel, I., Filakti, H., Alberman, E., Evans, S., 1992. Intergenerational studies of human birth weight from the 1958 birth cohort. I. Evidence for a multigenerational effect. British Journal of Obstetrics and Gynaecology 99, 67-74.

Ettner S.L., Frank R., Kessler R., 1997. The impact of psychiatric disorders on labor market outcomes. Industrial and Labor Relations Review 51, 64-81.

Fletcher J.M., Wolfe B.L., 2008. Child mental health and human capital accumulation: the case of ADHD revisited. Journal of Health Economics 27, 794-800.

Fletcher, J.M., 2010, Adolescent depression and educational attainment: results using sibling fixed effects, Health Economics 19, 855- 871.

Göhlmann, S., Schmidt, C.M., Tauchmann, H., 2010. Smoking initiation in Germany: The role of intergenerational transmission. Health Economics 19, 227-242.

Goode, A., Mavromaras, K. G., Smith, M., 2008. Intergenerational transmission of healthy eating behaviour and the role of household income. IZA Discussion Papers 3535. Institute for the Study of Labor (IZA).

Goodman, A., Joyce, R., Smith, J.P., 2011. The long shadow cast by childhood physical and mental problems on adult life. Proceedings of the National Academy of Science, Published online before print March 28, 2011, doi: 10.1073/pnas.1016970108

Grant, G., Nolan, M., Ellis, N., 1990. A reappraisal of the Malaise Inventory. Social Psychiatry and Psychiatric Epidemiology 25, 170-178.

Hamilton, V.H., Merrigan, P., Dufresne, E., 1997. Down and out: Estimating the relationship between mental health and unemployment. Health Economics 6, 397-406.

Harris, K.M. and Marmer, J.K., 1996. Poverty, paternal involvement, and adolescent well-being. Journal of Family Issues 17, September, 614 - 640.

Haveman, R., Wolfe, B., 1995. The determinants of children's attainments: A review of methods and findings. Journal of Economic Literature 33, 1829-1878.

Heckman, J.J., 2007. The economics, technology, and neuroscience of human capability formation. 
Proceedings of the National Academy of Sciences 104, 13250-13255.

Lee, C.-I., Solon, G., 2009. Trends in intergenerational income mobility. Review of Economics and Statistics 91, 766-772.

Loureiro, M.L., Sanz-de-Galdeano, A., Vuri, D., 2010. Smoking habits: like father, like son, like mother, like daughter? Oxford Bulletin of Economics and Statistics 72, 717-743.

Marcotte, D.E., Wilcox-Gök, V. 2001. Estimating the employment and earnings costs of mental illness: recent developments in the United States, Social Science \& Medicine 53, 21-27.

Marcotte, D.E., V. Wilcox-Gök, Redmon, D.P., 2000. The labor market effects of mental illness: The case of affective disorders. Research in Human Capital and Development. Connecticut: JAI Press.

Mare, R.D., 2011. A multigenerational view of inequality. Demography 48, 1-23.

Maurin, E., 2002. The impact of parental income on early schooling transitions. A re-examination using data over three generations, Journal of Public Economics 85, 301-332.

Mazumder, B., 2005. Fortunate sons: New estimates of intergenerational mobility in the United States using social security earnings data. Review of Economics and Statistics 87, 235-255.

McGee, R., Williams, S., Silva, P.A., 1986. An evaluation of the Malaise Inventory. Journal of Psychosomatic Research 30, 147-152.

Ojeda V.D., Frank R.G., McGuire T.G., Gilmer T.P., 2009. Mental illness, nativity, gender and labor supply. Health Economics 19, 396-421.

Osborne Groves, M., 2005. Personality and the intergenerational transmission of economic status. In: Unequal chances: family background and economic success. Bowles, S., Gintis, H., and Osborne Groves, M. eds. New York, NY: Russell Sage Foundation; Princeton and Oxford: Princeton University Press, 2005. Chapter 7: 208.

Oyserman, D., Mowbray, C.T., Meares, P.A., Firminger, K.B., 2000. Parenting among mothers with a serious mental illness. Amercian Journal of Orthopsychiatry 70, 296-315.

Palloni, A., 2006. Reproducing inequalities: Luck, wallets, and the enduring effects of childhood health. Demography 43, 587-615.

Pascal, M., Cantarero, D., 2009. Intergenerational health mobility: an empirical approach based on the ECHP. Applied Economics 41, 451-458.

Powdthavee, N., Vignoles, A., 2008. Mental health of parents and life satisfaction of children: A within-family analysis of intergenerational transmission of well-Being, Discussion Papers 08/20, Department of Economics, University of York.

Prager, L.M., 2009. Depression and suicide in children and adolescents. Paediatrics in Review 30, 199205. 
Rodger, B., Pickles, A., Power, C., Collishaw, S., Maughan, B., 1999. Validity of the Malaise Inventory in general population samples. Social Psychiatry and Psychiatric Epidemiology 34, 333-341.

Royer, H., 2009. Separated at girth: US twin estimates of the effects of birth-weight. American Economic Journal: Applied Economics 1, 49-85.

Rutter, M. , 2006. Genes and behaviour: Nature-nurture interplay explained. Blackwell, Oxford.

Rutter, M., Tizard, J., Whitmore, K., 1970. Education, health and behaviour. Longmans, London.

Schepman, K., Collishaw, S., Gardner, F., Maughan, B., Scott, J., Pickles, A., 2011. Do changes in parent mental health explain trends in youth emotional problems? Social Science \& Medicine 73, 293300.

Schmidt, C.M., Tauchmann, H., 2011. Heterogeneity in the intergenerational transmission of alcohol consumption. A quantile regression approach. Journal of Health Economics 30, 33-42.

Smith, J.P., Smith, G.C., 2010. Long-term economic costs of psychological problems during childhood. Social Science \& Medicine 71, 110-115.

Solon, G., 1999. Intergenerational mobility in the labor market, In: Orley C. Ashenfelter and David Card, Editor(s), Handbook of Labor Economics, Elsevier, Volume 3, Part 1, Chapter 29, 1761-1800.

Thorpe, K., Golding, J., MacGillivray, I., Greenwood, R., 1991. Comparison of prevalence of depression in mothers of twins and mothers of singletons. British Medical Journal 302, 875-878.

Whitaker, K.L., Jarvis, M.J., Beeken, R.J., Boniface, D., Wardle, J., 2010. Comparing maternal and paternal intergenerational transmission of obesity risk in a large population-based sample. American Journal of Clinical Nutrition 91, 1560-1567.

Zhang, X., Zhao, X., Harris, A., 2009. Chronic diseases and labour force participation in Australia. Journal of Health Economics 28, 91-108. 
Figure 1: Scatter-plot of Cohort Members' and their Mothers' Average Mental Health

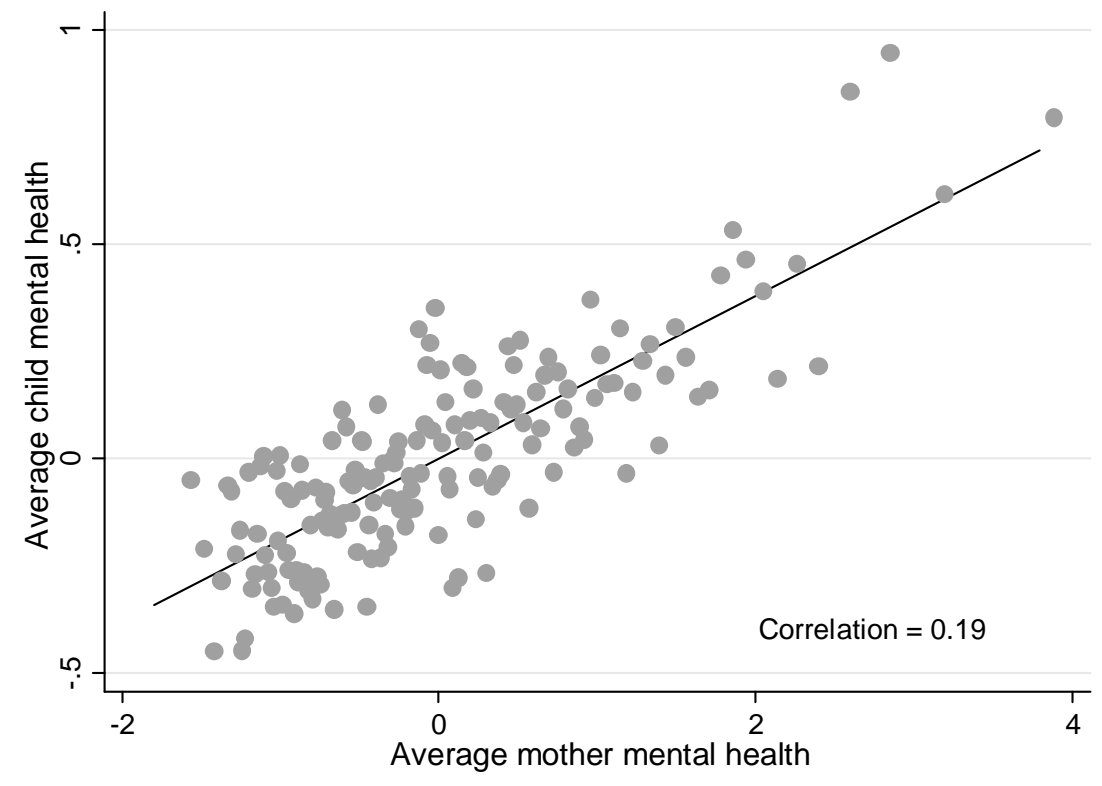

Figure 2: Relationship between Cohort Members' and their Mothers' Mental Health, on the Mental Health of Cohort Members' (Grand)children (Kernel Regression Estimates)

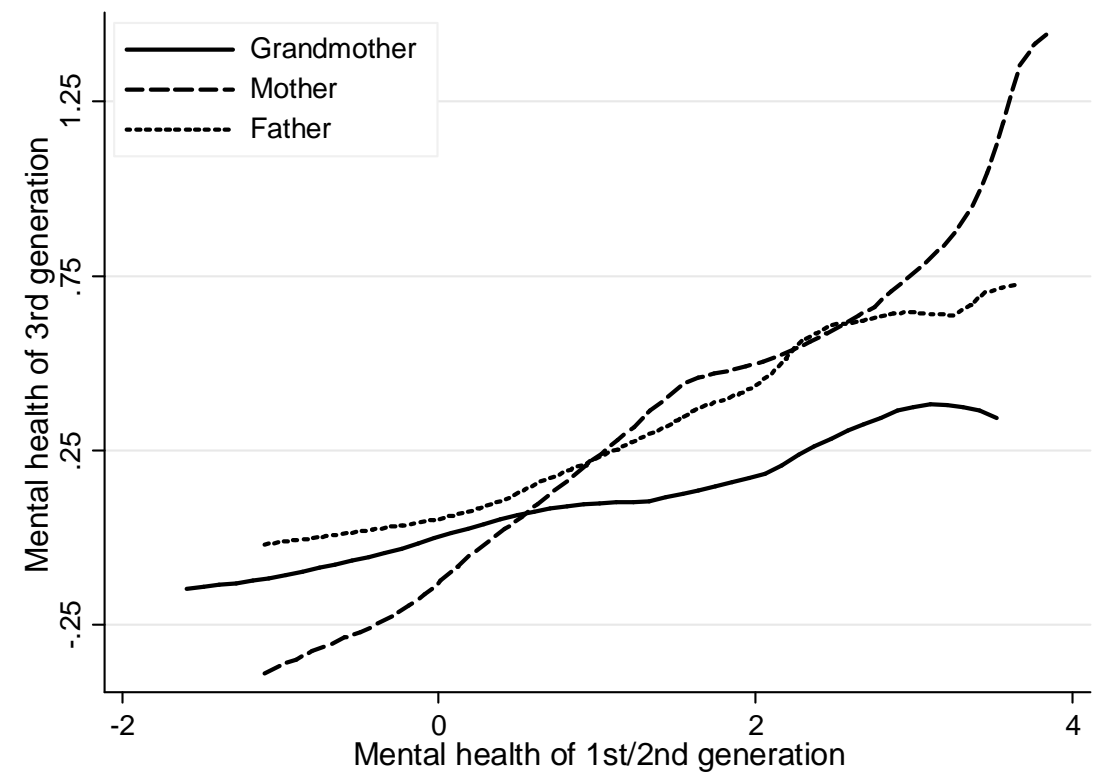


Table 1: Summary of Mental Health Questions Used to Form Index

\begin{tabular}{lcc}
\hline & \multicolumn{2}{c}{ Sample means } \\
\cline { 2 - 3 } & Mother & Child \\
\hline Do you feel tired most of the time? & 0.383 & 0.360 \\
Do you often feel miserable or depressed? & 0.270 & 0.189 \\
Do you often get worried about things? & 0.465 & 0.493 \\
Do you often get into a violent rage? & 0.142 & 0.057 \\
Do you often suddenly become scared for no good reason? & 0.113 & 0.080 \\
Are you easily upset or irritated? & 0.321 & 0.266 \\
Are you constantly keyed up and jittery? & 0.133 & 0.056 \\
Does every little thing get on your nerves and wear you out? & 0.133 & 0.055 \\
Does your heart often race like mad? & 0.127 & 0.082 \\
\hline
\end{tabular}

Note: Sample mean is the average over years, and can be interpreted as the proportion of individuals reporting to have experienced the symptom in a given year. The sample size used for all statistics is 8,194 . 
Table 2: Control Variable Summary Statistics

\begin{tabular}{|c|c|c|c|c|}
\hline Variable & Mean & Std. Dev. & Min & Max \\
\hline Male child & 0.470 & 0.499 & 0 & 1 \\
\hline \multicolumn{5}{|l|}{ Childhood Health 1970} \\
\hline Low birth weight $(<2,500 \mathrm{~g})$ & 0.054 & 0.226 & 0 & 1 \\
\hline Premature ( $<37$ weeks gestation) & 0.040 & 0.196 & 0 & 1 \\
\hline Forceps used during delivery & 0.097 & 0.296 & 0 & 1 \\
\hline Caesarean section delivery & 0.043 & 0.202 & 0 & 1 \\
\hline Congenital abnormalities & 0.039 & 0.192 & 0 & 1 \\
\hline Other illnesses or conditions & 0.032 & 0.176 & 0 & 1 \\
\hline Child is a twin or triplet & 0.019 & 0.137 & 0 & 1 \\
\hline Mother smoked during pregnancy & 0.384 & 0.486 & 0 & 1 \\
\hline \multicolumn{5}{|l|}{ Family characteristics 1975} \\
\hline Mother's age when she gave birth: $\leq 21$ & 0.188 & 0.390 & 0 & 1 \\
\hline Mother's age when she gave birth: $22-29$ & 0.582 & 0.493 & 0 & 1 \\
\hline Mother's age when she gave birth: $\geq 30$ & 0.231 & 0.421 & 0 & 1 \\
\hline Mother's education: minimum & 0.618 & 0.486 & 0 & 1 \\
\hline Mother's education: minimum +1 or 2 years & 0.257 & 0.437 & 0 & 1 \\
\hline Mother's education: minimum +3 or more years & 0.125 & 0.331 & 0 & 1 \\
\hline Child was breastfed & 0.394 & 0.489 & 0 & 1 \\
\hline Mother was employed & 0.357 & 0.479 & 0 & 1 \\
\hline Mother smoker & 0.400 & 0.490 & 0 & 1 \\
\hline No father in household & 0.048 & 0.214 & 0 & 1 \\
\hline Father social class: professionals & 0.078 & 0.268 & 0 & 1 \\
\hline Father social class: managerial \& other professionals & 0.216 & 0.411 & 0 & 1 \\
\hline Father social class: non-manual & 0.096 & 0.295 & 0 & 1 \\
\hline Father social class: manual & 0.452 & 0.498 & 0 & 1 \\
\hline Father social class: semi-skilled & 0.119 & 0.324 & 0 & 1 \\
\hline Father social class: unskilled & 0.037 & 0.190 & 0 & 1 \\
\hline Neighbourhood rating by interviewer: poor & 0.057 & 0.231 & 0 & 1 \\
\hline Neighbourhood rating by interviewer: average & 0.473 & 0.499 & 0 & 1 \\
\hline Neighbourhood rating by interviewer: well-to do & 0.260 & 0.439 & 0 & 1 \\
\hline Neighbourhood rating by interviewer: rural & 0.210 & 0.407 & 0 & 1 \\
\hline \multicolumn{5}{|l|}{ Childhood health 1975} \\
\hline Health problem & 0.389 & 0.488 & 0 & 1 \\
\hline Accident requiring medical attention & 0.428 & 0.495 & 0 & 1 \\
\hline \multicolumn{5}{|l|}{ Childhood test scores 1975} \\
\hline English Peabody vocabulary test child (Std) & 0.000 & 1.000 & -3.039 & 3.047 \\
\hline Copying ability test child (Std) & 0.000 & 1.000 & -2.388 & 1.654 \\
\hline Drawing test child (Std) & 0.000 & 1.000 & -3.155 & 3.804 \\
\hline \multicolumn{5}{|l|}{ Childhood mental health 1975} \\
\hline Rutter behavioural problems index (Std) & 0.000 & 1.000 & -1.663 & 6.354 \\
\hline \multicolumn{5}{|l|}{ Adulthood physical health 2000} \\
\hline Headaches, hay fever, bronchitis, asthma & 0.494 & 0.500 & 0 & 1 \\
\hline Eczema or other skin problem & 0.268 & 0.443 & 0 & 1 \\
\hline Back pain & 0.152 & 0.359 & 0 & 1 \\
\hline High blood pressure & 0.076 & 0.265 & 0 & 1 \\
\hline Hernia & 0.032 & 0.177 & 0 & 1 \\
\hline Epilepsy, convulsions & 0.027 & 0.161 & 0 & 1 \\
\hline Diabetes & 0.010 & 0.100 & 0 & 1 \\
\hline Cancer & 0.011 & 0.106 & 0 & 1 \\
\hline Ulcer, gallstones, IBS, ulcerative collitis & 0.116 & 0.321 & 0 & 1 \\
\hline Kidney or bladder problems & 0.069 & 0.253 & 0 & 1 \\
\hline
\end{tabular}


Table 3: Estimated Effects of Maternal Mental Health on Child Mental Health

\begin{tabular}{|c|c|c|c|c|c|c|c|}
\hline & (1) & (2) & (3) & (4) & (5) & (6) & (7) \\
\hline Average maternal mental health & $\begin{array}{l}0.190^{* * * *} \\
(0.011)\end{array}$ & $\begin{array}{c}0.182^{* * * *} \\
(0.011)\end{array}$ & $\begin{array}{l}0.170^{* * * *} \\
(0.011)\end{array}$ & $\begin{array}{l}0.168^{* * * *} \\
(0.011)\end{array}$ & $\begin{array}{l}0.163^{* * *} \\
(0.011)\end{array}$ & $\begin{array}{l}0.145^{* * * *} \\
(0.012)\end{array}$ & $\begin{array}{l}0.133^{* * * *} \\
(0.011)\end{array}$ \\
\hline \multicolumn{8}{|l|}{ Included control variables } \\
\hline Childhood health 1970 & $x$ & $\checkmark$ & $\checkmark$ & $\checkmark$ & $\checkmark$ & $\checkmark$ & $\checkmark$ \\
\hline Family characteristics 1975 & $x$ & $x$ & $\checkmark$ & $\checkmark$ & $\checkmark$ & $\checkmark$ & $\checkmark$ \\
\hline Childhood health 1975 & $x$ & $x$ & $x$ & $\checkmark$ & $\checkmark$ & $\checkmark$ & $\checkmark$ \\
\hline Childhood test scores 1975 & $x$ & $x$ & $x$ & $x$ & $\checkmark$ & $\checkmark$ & $\checkmark$ \\
\hline Childhood mental health 1975 & $x$ & $x$ & $x$ & $x$ & $x$ & $\checkmark$ & $\checkmark$ \\
\hline Adult physical health 2000 & $x$ & $x$ & $x$ & $x$ & $x$ & $x$ & $\checkmark$ \\
\hline Sample size & 8194 & 8194 & 8194 & 8194 & 8194 & 8194 & 8194 \\
\hline R-Squared & 0.036 & 0.070 & 0.078 & 0.079 & 0.083 & 0.086 & 0.122 \\
\hline
\end{tabular}

Note: Dependent variable in each OLS regression model is child mental health. Child and maternal mental health are standardized to be mean zero, standard deviation one. Standard errors are shown in parentheses. *, ** and *** denote significance at .10, .05 and .01 levels. Models (2) to (7) control for gender. Sets of control variables in specifications (2) to (7) are shown in Table 2.

Table 4: Estimated Effects of Maternal Mental Health on Child Mental Health for SubGroups and an Alternative Mental Health Measure (all using the Model 5 specification)

\begin{tabular}{|c|c|c|c|c|c|c|}
\hline \multirow[b]{2}{*}{ Mental health measure } & \multicolumn{2}{|c|}{ All cohort members } & \multicolumn{2}{|c|}{ Females } & \multicolumn{2}{|c|}{ Males } \\
\hline & Estimate & $\mathbf{N}$ & Estimate & $\mathbf{N}$ & Estimate & $\mathbf{N}$ \\
\hline (1) Maternal mental health & $\begin{array}{l}0.163^{* * *} \\
(0.011)\end{array}$ & 8194 & $\begin{array}{l}0.177^{* * *} \\
(0.015)\end{array}$ & 4345 & $\begin{array}{l}0.143^{* * *} \\
(0.016)\end{array}$ & 3849 \\
\hline $\begin{array}{l}\text { (2) Maternal mental health of cohort } \\
\text { members with own child }\end{array}$ & $\begin{array}{l}0.161^{* * *} \\
(0.017)\end{array}$ & 3486 & $\begin{array}{l}0.181^{* * *} \\
(0.021)\end{array}$ & 2189 & $\begin{array}{l}0.116^{* * *} \\
(0.026)\end{array}$ & 1297 \\
\hline $\begin{array}{l}\text { (3) Maternal mental health of cohort } \\
\text { members who rarely or never see mother }\end{array}$ & $\begin{array}{l}0.152^{* * *} \\
(0.024)\end{array}$ & 1760 & $\begin{array}{l}0.146^{* * *} \\
(0.035)\end{array}$ & 890 & $\begin{array}{l}0.141^{* * *} \\
(0.034)\end{array}$ & 870 \\
\hline (4) Binary poor maternal mental health & $\begin{array}{l}0.092^{* * *} \\
(0.013)\end{array}$ & 8194 & $\begin{array}{l}0.110^{* * *} \\
(0.019)\end{array}$ & 4345 & $\begin{array}{l}0.070^{* * * *} \\
(0.016)\end{array}$ & 3849 \\
\hline
\end{tabular}

Note: Estimates for rows (1)-(3) are from separate OLS regression models, with the displayed figures the coefficient on standardised maternal mental health (as per Table 3). Estimates for row (3) are from separate probit regression models, with the displayed figures the marginal effects for a binary poor maternal mental health indicator. Binary poor mental health indicator equals one if the mental health index is $\geq 1$ and zero otherwise; sample proportions are $15 \%$ for mothers and $15 \%$ for children (19\% for females, $11 \%$ for males). Models include the same set of covariates contained in model 5 in Table 3. In regular contact with mother represents at least weekly contact with mother in 2000 . Standard errors are shown in parentheses. *, ** and *** denote significance at $.10, .05$ and .01 levels. 
Table 5: Estimated Effect of Mental Health on Grandchild Mental Health

\begin{tabular}{l|ccccc}
\hline & $(\mathbf{1})$ & $\mathbf{( 2 )}$ & $\mathbf{( 3 )}$ & $\mathbf{( 4 )}$ & $\mathbf{( 5 )}$ \\
\hline Average grandmother mental health & $0.090^{* * *}$ & $0.086^{* * *}$ & 0.031 & - & - \\
& $(0.027)$ & $(0.027)$ & $(0.026)$ & & \\
Average parent (cohort member) mental & - & - & $0.305^{* * *}$ & $0.310^{* * *}$ & $0.480^{* * *}$ \\
health & & & $(0.027)$ & $(0.027)$ & $(0.153)$ \\
\hline Parent/Grandparent controls 1975 & $\checkmark$ & $\checkmark$ & $\checkmark$ & $\checkmark$ & $\checkmark$ \\
Parent controls 2000 & $x$ & $\checkmark$ & $\checkmark$ & $\checkmark$ & $\checkmark$ \\
Estimation method & OLS & OLS & OLS & OLS & 2 SLS \\
Number of Grandmothers & 1403 & 1403 & 1403 & 1403 & 1403 \\
Number of Grandchildren & 2265 & 2265 & 2265 & 2265 & 2265 \\
R-Squared & 0.082 & 0.092 & 0.176 & 0.175 & 0.148 \\
\hline
\end{tabular}

Note: Dependent variable in each regression model is grandchild mental health in 2004 measured using the Strength and Difficulties Questionnaire. Clustered standard errors are shown in parentheses. *, ** and *** denote significance at .10, .05 and .01 levels. Included in all models are the controls: grandchild gender and grandchild age dummies. Controls from 1975 are the set of covariates contained in model 5 in Table 2. Controls from 2000 are: age when left full-time continuous education; degree holder; marital status; number of people in household; whether any children in household; and log family income. The instrumental variable for parent mental health in column 5 is grandmother's mental health $(F=27.98)$.

Table 6: Estimated Effect of Mental Health on Grandchild Mental Health by Parent's Gender

\begin{tabular}{|c|c|c|c|c|c|}
\hline & (1) & (2) & (3) & (4) & (5) \\
\hline \multicolumn{6}{|l|}{ Cohort member female } \\
\hline Average grandmother mental health & $\begin{array}{l}0.103^{* * *} \\
(0.034)\end{array}$ & $\begin{array}{l}0.100^{* * *} \\
(0.033)\end{array}$ & $\begin{array}{c}0.034 \\
(0.031)\end{array}$ & - & - \\
\hline $\begin{array}{l}\text { Average mother (female cohort } \\
\text { member) mental health }\end{array}$ & - & - & $\begin{array}{l}0.334^{* * *} \\
(0.031)\end{array}$ & $\begin{array}{l}0.340^{* * *} \\
(0.031)\end{array}$ & $\begin{array}{l}0.503^{* * *} \\
(0.163)\end{array}$ \\
\hline Sample size & 1607 & 1607 & 1607 & 1607 & 1607 \\
\hline \multicolumn{6}{|l|}{ Cohort member male } \\
\hline Grandmother average mental health & $\begin{array}{c}0.048 \\
(0.040)\end{array}$ & $\begin{array}{c}0.047 \\
(0.040)\end{array}$ & $\begin{array}{c}0.018 \\
(0.040)\end{array}$ & & \\
\hline $\begin{array}{l}\text { Average father (male cohort } \\
\text { member) mental health }\end{array}$ & & & $\begin{array}{l}0.223^{* * *} \\
(0.045)\end{array}$ & $\begin{array}{l}0.226^{* * *} \\
(0.045)\end{array}$ & $\begin{array}{c}0.364 \\
(0.292)\end{array}$ \\
\hline Sample size & 658 & 658 & 658 & 658 & 658 \\
\hline Parent/Grandparent controls 1975 & $\checkmark$ & $\checkmark$ & $\checkmark$ & $\checkmark$ & $\checkmark$ \\
\hline Parent controls 2000 & $x$ & $\checkmark$ & $\checkmark$ & $\checkmark$ & $\checkmark$ \\
\hline Estimation method & OLS & OLS & OLS & OLS & 2SLS \\
\hline
\end{tabular}

Note: Dependent variable in each OLS regression model is grandchild mental health in 2004 measured using Strength and Difficulties Questionnaire. Clustered standard errors are shown in parentheses. *, ** and *** denote significance at $.10, .05$ and .01 levels. Included in all models are the controls: grandchild gender and grandchild age dummies. Controls from 1975 are the set of covariates contained in model 5 in Table 2. Controls from 2000 are: age when left full-time continuous education; degree holder; marital status; number of people in household; and whether any children in household. The instrumental variable for parent mental health in column 5 is grandmother's mental health ( $F=23.95$ for mothers and $F=12.95$ for fathers). 
Table 7: Estimated Effects of Maternal and Own Mental Health on Adult Economic Outcomes

\begin{tabular}{|c|c|c|c|c|c|c|c|c|c|c|}
\hline & \multicolumn{2}{|c|}{ Degree } & \multicolumn{4}{|c|}{ Subjective Financial Wellbeing } & \multicolumn{4}{|c|}{ Log Household Income } \\
\hline & $(1)$ & $(2)$ & (3) & $(4)$ & $(5)$ & $(6)$ & $(7)$ & $(8)$ & $(9)$ & $(10)$ \\
\hline Average maternal mental health & $\begin{array}{c}-0.014^{* * * *} \\
(0.005)\end{array}$ & $\begin{array}{l}-0.007 \\
(0.005)\end{array}$ & $\begin{array}{c}-0.059^{* * * *} \\
(0.009)\end{array}$ & $\begin{array}{c}-0.049^{* * * *} \\
(0.010)\end{array}$ & $\begin{array}{l}-0.018^{*} \\
(0.009)\end{array}$ & $\begin{array}{l}-0.017^{*} \\
(0.009)\end{array}$ & $\begin{array}{c}-0.036^{* * * *} \\
(0.008)\end{array}$ & $\begin{array}{c}-0.034^{* * * *} \\
(0.008)\end{array}$ & $\begin{array}{l}-0.021^{* *} \\
(0.008)\end{array}$ & $\begin{array}{c}-0.021^{* *} \\
(0.008)\end{array}$ \\
\hline Own mental health (age 10) & - & $\begin{array}{c}-0.023^{* * *} \\
(0.005)\end{array}$ & - & $\begin{array}{c}-0.033^{\text {**** }} \\
(0.009)\end{array}$ & $\begin{array}{c}-0.015 \\
(0.009)\end{array}$ & $\begin{array}{c}-0.010 \\
(0.009)\end{array}$ & - & $\begin{array}{l}-0.010 \\
(0.008)\end{array}$ & $\begin{array}{c}-0.003 \\
(0.008)\end{array}$ & $\begin{array}{c}0.003 \\
(0.008)\end{array}$ \\
\hline Own mental health (age 26-34) & - & - & - & - & $\begin{array}{c}-0.224^{* * * *} \\
(0.009)\end{array}$ & $\begin{array}{c}-0.221^{* * * *} \\
(0.009)\end{array}$ & - & - & $\begin{array}{c}-0.088^{* * * *} \\
(0.008)\end{array}$ & $\begin{array}{c}-0.083^{* * * *} \\
(0.008)\end{array}$ \\
\hline Maternal education high & $\begin{array}{c}0.230^{* * * *} \\
(0.019)\end{array}$ & $\begin{array}{c}0.229^{* * * *} \\
(0.019)\end{array}$ & $\begin{array}{c}0.031 \\
(0.030)\end{array}$ & $\begin{array}{c}0.029 \\
(0.030)\end{array}$ & $\begin{array}{c}0.023 \\
(0.029)\end{array}$ & $\begin{array}{c}-0.034 \\
(0.029)\end{array}$ & $\begin{array}{l}0.108^{* * * * *} \\
(0.027)\end{array}$ & $\begin{array}{c}0.108^{* * * *} \\
(0.027)\end{array}$ & $\begin{array}{l}0.105^{* * * *} \\
(0.026)\end{array}$ & $\begin{array}{c}0.030 \\
(0.026)\end{array}$ \\
\hline Father social class 1975: unskilled (age 5) & $\begin{array}{c}-0.167^{* * * *} \\
(0.015)\end{array}$ & $\begin{array}{c}-0.164^{* * * *} \\
(0.015)\end{array}$ & $\begin{array}{l}-0.114^{*} \\
(0.062)\end{array}$ & $\begin{array}{l}-0.108^{*} \\
(0.062)\end{array}$ & $\begin{array}{l}-0.101^{*} \\
(0.059)\end{array}$ & $\begin{array}{l}-0.039 \\
(0.059)\end{array}$ & $\begin{array}{c}-0.223^{* * * *} \\
(0.054)\end{array}$ & $\begin{array}{c}-0.222^{* * * *} \\
(0.054)\end{array}$ & $\begin{array}{c}-0.219^{* * * *} \\
(0.054)\end{array}$ & $\begin{array}{c}-0.140^{* * * *} \\
(0.053)\end{array}$ \\
\hline No father in household (age 5) & $\begin{array}{l}-0.007 \\
(0.041)\end{array}$ & $\begin{array}{c}-0.003 \\
(0.041)\end{array}$ & $\begin{array}{c}-0.240^{* * * *} \\
(0.073)\end{array}$ & $\begin{array}{c}-0.235^{\text {***** }} \\
(0.072)\end{array}$ & $\begin{array}{c}-0.181^{* * * *} \\
(0.070)\end{array}$ & $\begin{array}{c}-0.178^{* * *} \\
(0.069)\end{array}$ & $\begin{array}{c}-0.141^{* *} \\
(0.063)\end{array}$ & $\begin{array}{c}-0.140^{* * *} \\
(0.063)\end{array}$ & $\begin{array}{l}-0.117^{*} \\
(0.063)\end{array}$ & $\begin{array}{l}-0.115^{*} \\
(0.062)\end{array}$ \\
\hline English Peabody vocabulary test child (Std) (age 5) & $\begin{array}{c}0.039^{\text {***** }} \\
(0.005)\end{array}$ & $\begin{array}{c}0.038^{\text {***** }} \\
(0.005)\end{array}$ & $\begin{array}{c}0.045^{\text {***** }} \\
(0.010)\end{array}$ & $\begin{array}{c}0.044^{\text {***** }} \\
(0.010)\end{array}$ & $\begin{array}{c}0.034^{\text {***** }} \\
(0.009)\end{array}$ & $\begin{array}{c}0.026^{* * * *} \\
(0.009)\end{array}$ & $\begin{array}{c}0.057^{\text {**** }} \\
(0.009)\end{array}$ & $\begin{array}{c}0.057^{* * 3 *} \\
(0.009)\end{array}$ & $\begin{array}{c}0.053^{\text {**** }} \\
(0.009)\end{array}$ & $\begin{array}{c}0.043^{\text {**** }} \\
(0.008)\end{array}$ \\
\hline Copying ability test child (Std) (age 5) & $\begin{array}{c}0.062^{* * * *} \\
(0.006)\end{array}$ & $\begin{array}{c}0.061^{* * * *} \\
(0.006)\end{array}$ & $\begin{array}{c}0.053^{* * * *} \\
(0.011)\end{array}$ & $\begin{array}{c}0.051^{* * * *} \\
(0.011)\end{array}$ & $\begin{array}{c}0.043^{* * *} \\
(0.010)\end{array}$ & $\begin{array}{c}0.030^{* * * *} \\
(0.010)\end{array}$ & $\begin{array}{c}0.065^{* * *} \\
(0.009)\end{array}$ & $\begin{array}{c}0.064^{* * * *} \\
(0.009)\end{array}$ & $\begin{array}{c}0.061^{\text {**** }} \\
(0.009)\end{array}$ & $\begin{array}{c}0.043^{* * * *} \\
(0.009)\end{array}$ \\
\hline Cohort member has degree level qualification (age 30) & - & - & - & - & - & $\begin{array}{c}0.245^{* * * *} \\
(0.022)\end{array}$ & - & - & - & $\begin{array}{c}0.321^{\text {**** }} \\
(0.019)\end{array}$ \\
\hline Sample size & 8194 & 8194 & 8194 & 8194 & 8194 & 8194 & 8058 & 8058 & 8058 & 8058 \\
\hline
\end{tabular}

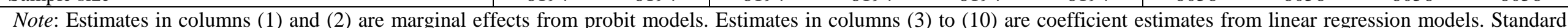

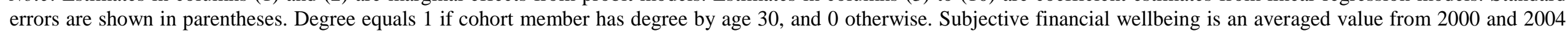

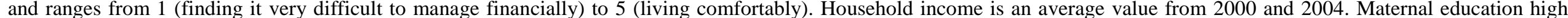

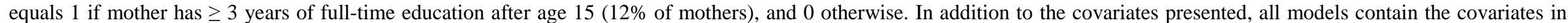
Model (5) from Table 2 (i.e. childhood health 1970 \& 1975, family characteristics, and test scores 1975). 


\section{APPENDIX}

Table A1: Determinants of child's mental health (Model 5 specification)

\begin{tabular}{|c|c|c|c|c|c|c|}
\hline & \multicolumn{2}{|c|}{ Full Sample } & \multicolumn{2}{|c|}{ Females } & \multicolumn{2}{|c|}{ Males } \\
\hline Average maternal mental health & $0.163^{* * *}$ & $(0.011)$ & $0.177^{* * * *}$ & $(0.015)$ & $0.143^{* * *}$ & $(0.016)$ \\
\hline Male & $-0.335^{* * *}$ & $(0.022)$ & - & - & - & - \\
\hline Low birth weight $(<2,500 \mathrm{~g})$ & 0.032 & $(0.052)$ & -0.032 & $(0.072)$ & 0.101 & $(0.075)$ \\
\hline Premature (<37 weeks gestation) & 0.019 & $(0.059)$ & -0.008 & $(0.084)$ & 0.038 & $(0.083)$ \\
\hline Forceps used during delivery & $-0.089^{* *}$ & $(0.036)$ & -0.085 & $(0.052)$ & $-0.096^{*}$ & $(0.051)$ \\
\hline Caesarean section delivery & -0.023 & $(0.054)$ & $-0.149^{*}$ & $(0.077)$ & 0.105 & $(0.075)$ \\
\hline Congenital abnormalities & $0.112^{* *}$ & $(0.056)$ & 0.054 & $(0.079)$ & $0.189^{* *}$ & $(0.080)$ \\
\hline Other illnesses or conditions & $0.125^{* *}$ & $(0.062)$ & $0.226^{* *}$ & $(0.091)$ & 0.033 & $(0.084)$ \\
\hline Twin or triplet & 0.037 & $(0.081)$ & 0.017 & $(0.120)$ & 0.036 & $(0.111)$ \\
\hline Mother smoked during pregnancy & 0.031 & $(0.030)$ & 0.020 & $(0.042)$ & 0.033 & $(0.044)$ \\
\hline Mother's age when she gave birth $\leq 21$ & 0.017 & $(0.029)$ & -0.003 & $(0.041)$ & 0.039 & $(0.041)$ \\
\hline Mother's age when she gave birth $\geq 30$ & $0.054^{* *}$ & $(0.026)$ & 0.053 & $(0.037)$ & 0.052 & $(0.038)$ \\
\hline Mother's education is minimum +1 or 2 years & -0.028 & $(0.026)$ & -0.050 & $(0.037)$ & -0.002 & $(0.038)$ \\
\hline Mother's education is minimum +3 or more years & -0.033 & $(0.037)$ & -0.063 & $(0.052)$ & 0.008 & $(0.052)$ \\
\hline Mother breastfed & $0.044^{*}$ & $(0.023)$ & $0.074^{* *}$ & $(0.033)$ & 0.016 & $(0.033)$ \\
\hline Mother employed in 1975 & -0.024 & $(0.023)$ & $-0.058^{*}$ & $(0.033)$ & 0.012 & $(0.033)$ \\
\hline Mother smoker in 1975 & 0.046 & $(0.031)$ & 0.059 & $(0.043)$ & 0.039 & $(0.045)$ \\
\hline No father in household & $0.252^{* * *}$ & $(0.087)$ & $0.223^{*}$ & $(0.127)$ & $0.276^{* *}$ & $(0.121)$ \\
\hline Father social class 1975: managerial \& other profs & 0.031 & $(0.047)$ & -0.023 & $(0.067)$ & 0.085 & $(0.066)$ \\
\hline Father social class 1975: non-manual & 0.063 & $(0.055)$ & 0.093 & $(0.079)$ & 0.031 & $(0.077)$ \\
\hline Father social class 1975: manual & 0.033 & $(0.047)$ & -0.005 & $(0.066)$ & 0.072 & $(0.066)$ \\
\hline Father social class 1975: semi-skilled & $0.097^{*}$ & $(0.055)$ & 0.010 & $(0.077)$ & $0.204^{* * *}$ & $(0.079)$ \\
\hline Father social class 1975: unskilled & 0.049 & $(0.074)$ & 0.102 & $(0.105)$ & -0.019 & $(0.105)$ \\
\hline Neighbourhood rating 1975: poor & $0.125^{* *}$ & $(0.050)$ & $0.137^{* *}$ & $(0.068)$ & 0.109 & $(0.073)$ \\
\hline Neighbourhood rating 1975: well-to do & -0.039 & $(0.030)$ & -0.029 & $(0.042)$ & -0.055 & $(0.042)$ \\
\hline Neighbourhood rating 1975: rural & -0.046 & $(0.030)$ & -0.024 & $(0.042)$ & -0.065 & $(0.043)$ \\
\hline Health problem in 1975 & $0.062^{* * *}$ & $(0.023)$ & $0.070^{* *}$ & $(0.032)$ & $0.056^{*}$ & $(0.032)$ \\
\hline Accident requiring medical attention in 1975 & 0.004 & $(0.022)$ & -0.019 & $(0.032)$ & 0.028 & $(0.031)$ \\
\hline English Peabody vocabulary test in 1975 & $-0.050^{* * *}$ & $(0.013)$ & $-0.062^{* * *}$ & $(0.019)$ & $-0.038^{* *}$ & $(0.018)$ \\
\hline Drawing test in 1975 & -0.000 & $(0.012)$ & -0.006 & $(0.018)$ & 0.004 & $(0.017)$ \\
\hline Copying ability test in 1975 & $-0.039^{* * *}$ & $(0.013)$ & $-0.047^{* * *}$ & $(0.018)$ & $-0.033^{*}$ & $(0.018)$ \\
\hline Sample size & 8194 & & 4345 & & 3849 & \\
\hline R-squared & 0.083 & & 0.067 & & 0.050 & \\
\hline Adjusted R-squared & 0.078 & & 0.057 & & 0.039 & \\
\hline
\end{tabular}

Note: Each column of estimates represents an OLS regression model with standardised child mental health as the dependent variable. Models include the same set of covariates contained in model 5 in Table 2. Standard errors are shown in parentheses. *, ** and $* * *$ denote significance at $.10, .05$ and .01 levels. 
Table A2: Determinants of Adult Economic Outcomes

\begin{tabular}{|c|c|c|c|c|c|c|}
\hline & \multicolumn{2}{|c|}{ Degree } & \multicolumn{2}{|c|}{ Financial Wellbeing } & \multicolumn{2}{|c|}{ Log Household Income } \\
\hline Maternal mental health & -0.007 & $(0.005)$ & $-0.017^{*}$ & $(0.009)$ & $-0.021^{* * *}$ & $(0.008)$ \\
\hline Own mental health (age 10) & $-0.023^{* * *}$ & $(0.005)$ & -0.010 & $(0.009)$ & 0.003 & $(0.008)$ \\
\hline Own mental health (age 26-34) & - & - & $-0.221^{\text {*** }}$ & $(0.009)$ & $-0.083^{* * *}$ & $(0.008)$ \\
\hline Degree holder & - & - & $0.245^{* * *}$ & $(0.022)$ & $0.321^{* * * *}$ & $(0.019)$ \\
\hline Male & 0.009 & $(0.010)$ & $-0.072^{* * * *}$ & $(0.018)$ & $-0.087^{* * *}$ & $(0.016)$ \\
\hline Low birth weight $(<2,500 \mathrm{~g})$ & -0.005 & $(0.024)$ & 0.048 & $(0.041)$ & -0.016 & $(0.037)$ \\
\hline Premature ( $<37$ weeks gestation) & 0.010 & $(0.028)$ & 0.028 & $(0.046)$ & 0.033 & $(0.041)$ \\
\hline Forceps used during delivery & $0.060^{* * *}$ & $(0.017)$ & 0.037 & $(0.029)$ & -0.016 & $(0.026)$ \\
\hline Caesarean section delivery & 0.041 & $(0.025)$ & 0.060 & $(0.043)$ & 0.010 & $(0.038)$ \\
\hline Congenital abnormalities & 0.005 & $(0.025)$ & 0.017 & $(0.044)$ & 0.023 & $(0.039)$ \\
\hline Other illnesses or conditions & -0.010 & $(0.027)$ & 0.064 & $(0.049)$ & -0.003 & $(0.044)$ \\
\hline Twin or triplet & 0.009 & $(0.039)$ & -0.038 & $(0.064)$ & 0.069 & $(0.057)$ \\
\hline Mother smoked during pregnancy & $-0.047^{* * *}$ & $(0.013)$ & 0.010 & $(0.024)$ & 0.026 & $(0.021)$ \\
\hline Mother's age when she gave birth $\leq 21$ & $-0.034^{* * *}$ & $(0.013)$ & -0.031 & $(0.023)$ & 0.007 & $(0.021)$ \\
\hline Mother's age when she gave birth $\geq 30$ & $0.021^{*}$ & $(0.012)$ & -0.005 & $(0.021)$ & $-0.035^{*}$ & $(0.019)$ \\
\hline Mother's education is minimum +1 or 2 years & $0.098^{* * *}$ & $(0.012)$ & -0.010 & $(0.021)$ & 0.026 & $(0.019)$ \\
\hline Mother's education is minimum +3 or more years & $0.229^{* * *}$ & $(0.019)$ & -0.034 & $(0.029)$ & 0.030 & $(0.026)$ \\
\hline Mother breastfed & $0.033^{* * *}$ & $(0.010)$ & 0.008 & $(0.018)$ & -0.011 & $(0.016)$ \\
\hline Mother employed in 1975 & -0.005 & $(0.010)$ & 0.016 & $(0.018)$ & 0.025 & $(0.016)$ \\
\hline Mother smoker in 1975 & $-0.030^{* *}$ & $(0.014)$ & -0.030 & $(0.025)$ & -0.009 & $(0.022)$ \\
\hline No father in household & -0.003 & $(0.041)$ & $-0.178^{* *}$ & $(0.069)$ & $-0.115^{*}$ & $(0.062)$ \\
\hline Father social class 1975: managerial \& other profs & $-0.088^{* * *}$ & $(0.015)$ & 0.034 & $(0.037)$ & -0.018 & $(0.033)$ \\
\hline Father social class 1975: non-manual & $-0.112^{* * *}$ & $(0.015)$ & 0.033 & $(0.044)$ & -0.010 & $(0.039)$ \\
\hline Father social class 1975: manual & $-0.175^{* * *}$ & $(0.017)$ & -0.006 & $(0.037)$ & $-0.067^{* *}$ & $(0.033)$ \\
\hline Father social class 1975: semi-skilled & $-0.171^{* * *}$ & $(0.012)$ & -0.049 & $(0.044)$ & -0.054 & $(0.039)$ \\
\hline Father social class 1975: unskilled & $-0.164^{* * *}$ & $(0.015)$ & -0.039 & $(0.059)$ & $-0.140^{* * *}$ & $(0.053)$ \\
\hline Neighbourhood rating 1975: poor & $0.048^{*}$ & $(0.027)$ & $-0.149^{* * *}$ & $(0.039)$ & -0.051 & $(0.035)$ \\
\hline Neighbourhood rating 1975: well-to do & $0.048^{* * *}$ & $(0.013)$ & $0.050^{* *}$ & $(0.024)$ & 0.019 & $(0.021)$ \\
\hline Neighbourhood rating 1975: rural & 0.008 & $(0.014)$ & -0.002 & $(0.024)$ & -0.015 & $(0.021)$ \\
\hline Health problem in 1975 & -0.003 & $(0.010)$ & 0.011 & $(0.018)$ & $0.034^{* *}$ & $(0.016)$ \\
\hline Accident requiring medical attention in 1975 & -0.004 & $(0.010)$ & 0.000 & $(0.018)$ & -0.011 & $(0.016)$ \\
\hline English Peabody vocabulary test in 1975 & $0.038^{* * *}$ & $(0.005)$ & $0.026^{* * *}$ & $(0.009)$ & $0.043^{* * *}$ & $(0.008)$ \\
\hline Drawing test in 1975 & $0.016^{* * *}$ & $(0.006)$ & -0.003 & $(0.010)$ & -0.002 & $(0.009)$ \\
\hline Copying ability test in 1975 & $0.061^{* * *}$ & $(0.006)$ & $0.030^{* * *}$ & $(0.010)$ & $0.043^{* * *}$ & $(0.009)$ \\
\hline Sample size & 8194 & & 8194 & & 8058 & \\
\hline
\end{tabular}

Note: Estimates in columns (1) are marginal effects from a probit model. Estimates in columns (2) and (3) are coefficient estimates from linear regression models. Standard errors are shown in parentheses. Degree equals 1 if cohort member has degree by age 30, and 0 otherwise. Subjective financial wellbeing is an averaged value from 2000 and 2004 and ranges from 1 (finding it very difficult to manage financially) to 5 (living comfortably). Household income is an average value from 2000 and 2004. 